\title{
O PAPEL DO GÊNERO/SEXO NOS ESTUDOS SOCIOLINGÜÍSTICOS DE VARIAÇÃO/MUDANÇA
}

\author{
Cristine Gorski Severo - Doutoranda em Lingüística (UFSC) \\ E-mail: crisgorski2@hotmail.com
}

Resumo: Trata-se, neste artigo, de analisar a maneira pela qual os estudos sociolingüísticos de variação/mudança consideram a questão do gênero. Percebe-se que, em uma abordagem tradicional, o gênero é visto como categoria biológica, conforme demonstram os estudos de Labov e de Chambers. Já em uma perspectiva crítica, o gênero é tido como construção social, cultural e histórica, conforme mostram as pesquisas que lidam com as redes sociais e as comunidades de prática. Defende-se que os estudos sociolingüísticos não podem se limitar à análise dos fenômenos lingüísticos sem que uma correlação com o processo identificatório dos sujeitos seja feita (o que inclui o gênero); e isso vai além de categorias estatisticamente mensuráveis.

Palavras-chave: variação/ mudança, gênero, sexo, identidade.

\section{INTRODUÇÃO}

Este artigo aborda a relação estabelecida entre linguagem e gênero pelos estudos sociolingüísticos que tratam da variação/mudança. Muitos de tais estudos se pautam em uma visão tradicional de gênero, que o limita à noção de sexo biológico - como demonstram alguns trabalhos de Labov e de Chambers. Contudo, um olhar mais crítico sobre a maneira pela qual linguagem e gênero se relacionam caracteriza as pesquisas variacionistas que lidam com micro categorias de análise, que são as redes sociais e as comunidades de prática. Nessas abordagens, o gênero é tido como um aspecto da identidade, que é construído social e culturalmente através de interações e práticas sociais. O fenômeno da variação, especialmente na abordagem da comunidade de prática, é visto como estando intrinsecamente relacionado ao processo de constituição da identidade dos sujeitos (incluindo o gênero).

Para contextualizar a questão do gênero nos estudos sociolingüísticos de variação/mudança, são expostas a seguir as conclusões amplamente aceitas pela área em relação ao assunto e as explicações dadas para essas conclusões. Tais conclusões e explicações são compartilhadas, em grande parte, pela perspectiva tradicional da área.

As conclusões são (Chambers, 1995; Labov, 1972):

(i) As mulheres utilizam menos variantes estigmatizadas do que os homens do mesmo grupo social e sob as mesmas circunstâncias; elas usam mais as variantes de prestígio do que os homens. 
(ii) As mulheres se adaptam lingüisticamente melhor do que os homens a uma variada gama de situações sociolingüísticas.

As explicações comuns para essas conclusões incluem:

(i) Conservadorismo - as mulheres (classe média) tendem a ser mais conservadoras do que os homens e a inovar menos do que eles.

(ii) Status - as mulheres tentam, ao utilizarem as formas de prestígio, alcançar status social: elas possuem mais consciência/sensibilidade em relação ao status social do que os homens em virtude da posição social insegura que elas ocupam.

(iii) Solidariedade - as mulheres, em suas redes sociais, não sofrem as mesmas pressões do que os homens para utilizarem as normas do vernáculo, uma vez que os homens tendem a participar de redes mais densas e múltiplas do que as mulheres.

Tais explicações são, contudo, alvo de questionamentos: Para Cameron e Coates (1990), por exemplo, a noção de conservadorismo é relativa e não pode explicar o comportamento das mulheres como um único grupo. Já em relação ao status, as estudiosas sugerem que a crença de que as mulheres são mais sensíveis ao status origina-se do machismo presente nas normas: enquanto o comportamento do homem é tido como normal, o das mulheres deve ser explicado, pois é "diferente". Quanto à solidariedade, Cameron e Coates (1990) criticam os critérios utilizados para se determinar a multiplicidade das redes sociais - vinculam-se, geralmente, ao estilo de vida masculino (trabalho vs. lazer).

Ademais, há as críticas feministas sobre os estudos tradicionais da sociolingüística: tais estudos seriam limitados, pois focam os estereótipos e preconceitos presentes nos instrumentos de medida, nos postulados teóricos e nas interpretações individuais. As críticas questionam: (i) a forma pela qual as mulheres são tratadas - como desviantes ou periféricas (as informantes mulheres, em alguns casos, são inexistentes, pois acredita-se que a fala do homens é mais próxima do vernáculo); (ii) os instrumentos de medida - são inventados por homens e destinados, prioritariamente, a eles; (iii) as explicações para as diferenças lingüísticas em relação ao gênero - são dadas a partir de esteriótipos sexuais. (Cameron, 1990)

Por fim, para Cameron e Coates (1990), a visão tradicional tem sido bastante produtiva na identificação das diferenças lingüísticas em relação ao sexo; porém, pouco se fala sobre as motivações para essas diferenças. 
A seguir, a correlação entre linguagem e gênero (proposta pelos estudos sociolingüísticos que tratam de variação/mudança) é apresentada e discutida em quatro itens: um que trata da relação entre gênero e sexo biológico; outra que aborda o paradoxo do sexo (estudos de Labov, 2001); um terceiro que expõe os estudos das redes sociais e um último que vincula um olhar sobre o gênero como construção social e cultural às pesquisas envolvendo as comunidades de prática. Os dois primeiros itens abordam aspectos referentes à perspectiva tradicional, enquanto os últimos tratam de u ma perspectiva crítica em relação à noção de gênero. Por fim, defende-se a importância de um olhar crítico sobre a questão do gênero, de forma que as explicações sobre os fenômenos de variação/mudança considerem, necessariamente, a questão do processo de formação da identidade dos sujeitos.

\section{Gênero vs. Sexo}

Sobre os conceitos de gênero utilizados nos estudos sociolingüísticos, Wodak e Benke (1997) afirmam que as pesquisas correlacionando linguagem e gênero tiveram início com os trabalhos de Labov, nos anos 60. Nessa tradição, o gênero é visto como o sexo biológico, sendo que não são feitas considerações acerca da construção social do gênero. A intenção, nesse caso, é mostrar a correlação existente entre as variáveis lingüísticas e o sexo (entre outras categorias sociais); com isso, o gênero é controlado da mesma forma que a escolaridade, a idade ou a classe social - importam, apenas, na medida em que são passíveis de serem estatisticamente medidos.

Na tentativa de distinguir gênero e sexo, Chambers (1995), por exemplo, define duas categorias de variação:

I. Baseada no gênero (gender-based variability) - nesse caso, as diferenças lingüísticas são explicadas em termos dos papéis desempenhados por homens e mulheres em relação à mobilidade deles em uma dada comunidade: quanto menor for o contato social e a variação geográfica de homens ou mulheres, maior será o uso, por esses indivíduos, das variantes do seu grupo de contato (p. 125-126). Exemplo: Nichols, 1983 (In Chambers, 1995) identificou, em uma comunidade de pessoas negras na Carolina do Sul, que os homens tendem a utilizar as variantes do dialeto local mais freqüentemente do que as mulheres. Explicação: esses 
padrões não são explicados pela questão do gênero em si mesmo, mas refletem diferenças individuais e grupais em relação à mobilidade e às interações com grupos não-nativos. As mulheres, por exemplo, tendem a se deslocar geograficamente e a ter relações sociais mais diversificadas do que os homens.

Nesse tipo de variação, o gênero desempenha um papel secundário em relação à mobilidade: trata-se, portanto, de variação baseada na mobilidade e não no gênero. A justificativa de Chambers (1995) para o nome atribuído a esse tipo de variação é que a mobilidade é determinante na existência de diferenças lingüísticas entre homens e mulheres.

II. Baseada no sexo (sex-based variability) - nesse caso, explica-se as diferenças lingüísticas a partir de diferenças biológicas (neuropiscológicas) entre homens e mulheres, que existem mesmo quando os papéis atribuídos ao gênero são ausentes (p. 104). Exemplificando, testes demonstram que: as mulheres possuem mais vantagens do que os homens em relação ao comportamento verbal; os homens tendem a apresentar distúrbios verbais mais freqüentemente do que as mulheres; os homens são mais propensos a apresentar distúrbio de leitura e afasia (após caso de acidente cerebral); e eles são quatro vezes mais propensos a sofrer de autismo infantil e de dislexia do que as mulheres (p. 133).

Correlacionando os dois tipos de variação, Chambers (1995) levanta a hipótese de que a tendência de as mulheres assumirem papéis (relacionados ao gênero) que exijam maior mobilidade do que os homens pode ser o resultado (e não a causa) de sua vantagem sociolingüística inata.

Apesar de estipular essas duas categorias de variação, percebe-se que Chambers é bastante tradicional ao pautar a questão do gênero no sexo biológico e não no processo de produção da identidade ao qual o gênero - tido como construção social está interligado. Na mesma direção de Chambers estão os estudos de Labov, os quais serão sucintamente abordados na próxima seção.

Diferentemente dos autores acima, Eckert e McConnell-Ginet (2003) defendem que ambas as categorias - sexo e gênero - não podem ser consideradas sinônimos, visto que o segundo é a elaboração social do primeiro. Para as autoras, por exemplo, a dicotomia menina-menino é a primeira a partir da qual a nossa identidade é formada. Meninas e meninos aprendem a ser femininas ou masculinos através das práticas 
sociais que existem nas diversas comunidades às quais eles pertencem. Assim, tem-se que: (i) meninas e meninos são tratados diferentemente por seus pais em relação ao padrão lingüístico que esses utilizam, à maneira pela qual eles brincam com seus filhos ou aos brinquedos que eles escolhem para suas filhas e filhos; (ii) as meninas e os meninos se envolvem com os mesmos grupos sexuais durante grande parte da infância, o que significa que meninas e meninos são socializados em diferentes culturas de gênero - isto, por sua vez, influencia o comportamento verbal que elas/eles desenvolvem.

\section{O paradoxo do gênero}

Os estudos de Labov (2001) em uma comunidade de fala na Filadélfia demonstraram o que o lingüista chamou de paradoxo do gênero (Gender Paradox), que inclui duas afirmações:

(i) quando se trata de mudanças vindas de cimalil (changes from above), as mulheres utilizam mais as formas de prestígio do que os homens.

(ii) quando se trata de mudanças vindas de baixo (changes from below), as mulheres são as líderes da mudança lingüística, o que significa que quando as mudanças iniciam, as mulheres são mais rápidas do que os homens em utilizarem o novo símbolo social. Assim, ao iniciarem a mudança lingüística, elas produzem uma diferenciação de gênero (entre elas e os homens).

No primeiro caso, os dados levantados por Labov demonstraram que as mulheres utilizam variáveis menos estigmatizadas do que os homens. Em uma correlação do gênero com a classe social, o sociolingüista (2001) concluiu que as mulheres da classe média baixa fazem mais esforço para usar as formas de prestígio (e evitar as estigmatizadas) do que as mulheres de classe baixa ou alta.

Para explicar esse fenômeno, Labov segue uma perspectiva tradicional, pautandose nos trabalhos de Schilling-Estes, 1998 (In Labov, 2001): devido às mulheres possuírem menor poder econômico, elas asseguram-se através do capital simbólico (linguagem). Assim, Labov sugere que o comportamento cuidadoso das mulheres em relação ao uso das variáveis de prestígio estaria refletindo a fraqueza socioeconômica 
delas que, por fim, geraria insegurança psicológica e sociológica. Contudo, Labov parece acreditar que as diferenças lingüísticas estão muito mais próximas da mobilidade social do que da insegurança social. Assim, o lingüista oferece uma possível interpretação para a conformidade das mulheres ao uso das formas de prestígio: reflete a responsabilidade que elas assumem pela futura mobilidade dos filhos, preparando o capital simbólico deles (p. 278). O papel das mulheres é visto, nessa explicação, em relação à educação dos filhos.

No segundo caso, Labov parece se distanciar de uma perspectiva tradicional ao focar os indivíduos (as mulheres) em suas redes sociais, de forma a identificar os líderes da mudança. Suas conclusões apontam que as líderes possuem uma posição central em suas redes sociais (elas influenciam seus amigos e parentes) e elas também mantém relações fora de suas localidades (demonstra a rota da mudança). Nas pesquisas de Labov, as líderes possuem um aposição econômica e social central em suas redes sociais locais e suas ações como líderes podem ser explicadas a partir das histórias de seus contatos sociais em anos de formação, que inclui uma história de não conformidade (p. 410).

Para tratar de uma visão crítica a respeito da relação entre gênero e variação/mudança lingüística, são acionadas, a seguir, as noções de redes sociais e de comunidades de prática.

\section{As redes sociais}

Milroy e Milroy (1987) propõem o estudo da variação lingüística a partir das redes sociais; tal estudo se baseia na análise nos relacionamentos informais de indivíduos que estão ligados entre si por redes de relacionamentos - quando os laços entre esses indivíduos são fortes, as redes atuam como mecanismos normativos. Em suas pesquisas sobre a comunidade de Belfast (1980), Milroy percebeu que em um dos grupos estudados, as mulheres apresentavam variáveis mais próximas do vernáculo do que os homens, o que foi explicado pelo fato dessas mulheres pertencerem a redes densas, em função de certas interações e da questão do trabalho. Essa interpretação, segundo Cameron (1990), rompe com a forma tradicional de explicação das diferenças lingüísticas entre homens e mulheres - neste caso, Milroy se volta para aspectos 
individuais e materiais (como a questão do trabalho) para explicar as diferenças.

Em pesquisas posteriores, Milroy e Gordon (2003) assumem um posicionamento bastante crítico em relação ao gênero e ao sexo biológico: Os autores questionam a perspectiva tradicional que vincula o gênero à classe social para explicar o motivo que leva as mulheres a se aproximarem mais da norma de prestígio do que os homens. Segundo eles, com base na revisão de outras pesquisas, o fato de as mulheres utilizarem as variantes de prestígio não significa que elas valorizem essas variantes, mas sim que elas as criam; e essas variantes, preferidas pelas mulheres, passam a ser consideradas de prestígio. Dessa forma, os autores criticam a própria noção de norma de prestígio, que não é algo fixo e cristalizado, mas que muda constantemente.

Por fim, Milroy e Gordon (2003) defendem que generalizações descontextualizadas sobre a correlação entre gênero e linguagem podem ser problemáticas, uma vez que o gênero interage com outros fatores sociais, como a idade, e que os usos lingüísticos vinculados ao gênero (bem como os papéis sociais) sofrem influências históricas. Com isso, em diferentes gerações, o gênero afeta a linguagem com certas especificidades e isso se vincula às experiências de vida dos indivíduos, às ideologias e às categorias sociais existentes dentro de determinada comunidade (p. 108).

\section{Comunidades de prática}

Eckert (2000) propõe que os estudos da variação lingüística tenham como lócus d e análise as comunidades de prática, que podem ser entendidas como espaços interacionais de construção designificados sociais onde as identidades, tanto individuais como grupais, estão sendo constantemente construídas. Assim, o gênero é uma construção social que ocorre em práticas sociais, as quais se vinculam a outras categorias sociais.

Em seus estudos sobre a variação sociolingüística em alunos de uma escola de segundo grau dos arredores de Detroit, Eckert (2000) identificou dois grupos sociais: os burnouts (representa a cultura da classe trabalhadora - cultura local e pessoal), em 
oposição aos jocks (representa a cultura da classe média - cultura institucional). Nesses dois grupos, com ideologias, normas, histórias e estilos diferentes, Eckert (2000) localizou diferentes variáveis sociolingüísticas. Em suas análises, a lingüista percebeu que, em relação a algumas variáveis, as meninas tendem a utilizar a forma de prestígio; contudo, a maior parte das variáveis são utilizadas de forma diversificada e não são orientadas para o padrão; essa diversidade é o que caracterizaria melhor a fala das meninas (p. 122). Eckert defende que as diferenças lingüísticas em relação ao gênero devem ser avaliadas em relação aos grupos de gênero (e não a categorias sociais); tais grupos definem certos padrões de comportamento, certas formas de posicionamento no mundo e de auto-avaliação: por exemplo, é em referência às meninas do seu grupo que uma garota burnout vai se identificar.

Por fim, em sua teoria da variação tida como prática social, Eckert (2000) olha para os falantes como sujeitos que, ao se inserirem em práticas sociais, constituem categorias sociais e constroem (e respondem a) o significado social da variação. Com isso, é inerente ao fenômeno de variação/mudança lingüística o processo de constituição da identidade dos indivíduos, pois é nesse processo (que envolve também a constituição do gênero) que as variáveis lingüísticas assumem valor social (Eckert, 2000).

\section{Conclusão}

Neste artigo foram abordadas as maneiras pelas quais a sociolingüística que trata do fenômeno da variação/mudança tem correlacionado esse fenômeno com o gênero: para a perspectiva tradicional, o gênero é tido como uma categoria biológica (sexo), sendo passível de ser estatisticamente medido. Na tradição crítica, o gênero é visto como uma construção social, vinculado ao processo de formação da identidade dos indivíduos. Com isso, o estudo da variação/mudança pressupõe o estudo do processo de constituição das identidades.

Dado que identidade (gênero é um aspecto da identidade) e linguagem implicamse mutuamente, a sociolingüística não pode se limitar a um modelo essencialista que considera o gênero como uma categoria universal e previamente estabelecida, sem levar em conta que essa categoria é uma construção histórica, política e social, através 
da qual os indivíduos constituem suas identidades. Assim, argumenta-se em favor de que os trabalhos que tratam de variação/mudança devem contemplar as práticas sociais nas quais os indivíduos se engajam para constituir suas identidades (o gênero está implícito nessa constituição), pois é nessas comunidades de práticas que as variáveis assumem significado social e, a partir daí, se espalham (ou não) para o contexto social mais amplo.

\section{Referências bibliográficas}

CAMERON, D.; COATES, J. (orgs.). Women in their speech communities. Nova York: Longman, 1990.

CAMERON, D. Introduction. In CAMERON, D.; COATES, J. (orgs.), 1990. CAMERON, D.; COATES, J. Some problems in the sociolinguistic explanation of sex differences. In: CAMERON, D.; COATES, J. (orgs.), 1990.

CHAMBERS, J. K. Sociolinguistic Theory. Oxford: Blackwell, 1995.

ECKERT, P. Linguistic Variation as social practice. Oxford: Blackwell, 2000.

ECKERT, P.; McCONNELL-GINET, S. Language and Gender. Cambridge: Cambridge University Press, 2003.

LABOV, W. Principles of Linguistic Change - Social Factors. Oxford: Blackwell, 2001.

. Principles of Linguistic Change: Internal Factors. Cambridge: Blackwell Püblishers, 1994.

MILROY, L. Language and social networks. Oxford: Blackwell, 1987

MILROY, L.; GORDON, M. Sociolinguistics - Method and Interpretation. Oxford: Blackwell, 2003.

WODAK, R.; BENKE, G. Gender as a sociolinguistic variable: New perspectives on variation studies. In COULMAN, F. (org.), The handbook of sociolinguistics. Oxford: Blackwell, 1997.

[i] As mudanças de cima (from above) e de baixo (from below) referem-se aos níveis de consciência social e de posições sócio-econômicas. Para Labov (1994, p.78), "mudanças de cima são introduzidas pela classe social dominante, geralmente com consciência pública completa [...] Mudanças de baixo são mudanças sistemáticas que primeiro surgem no vernáculo, e representam a operação de fatores lingüísticos internos [...] elas estão completamente abaixo do nível de consciência social". 